\title{
Correction to: The validity and reproducibility of perceptually regulated exercise responses during combined arm + leg cycling
}

\author{
M. Hill ${ }^{1}$ (1) $\cdot$ M. Puddiford ${ }^{2} \cdot$ C. Talbot $^{2} \cdot$ M. Price $^{1}$
}

Published online: 6 October 2020

(c) Springer-Verlag GmbH Germany, part of Springer Nature 2020

\section{Correction to: European Journal of Applied Physiology https://doi.org/10.1007/s00421-020-04444-z}

The original version of this article unfortunately contained a mistake. The correct information is given below.

In the second sentence of the "Method" section of the abstract, the authors stated that "On three subsequent occasions, participants undertook combined arm + leg cycling trials using two modified Monark ergometers involving three bouts of exercise at RPE 9, 13 and 17, in that order". The order of exercise was actually RPE 13, 9 and 17.
The original article can be found online at https://doi.org/10.1007/ s00421-020-04444-z.

\section{Hill}

matt.hill@coventry.ac.uk

1 Centre for Sport, Exercise and Life Sciences, School of Life Sciences, Coventry University, Whitefriars Street, Coventry CV1 2DS, UK

2 Sport, Exercise and Life Sciences, Faculty of Health and Society, University of Northampton, Northamptonshire, UK
Publisher's Note Springer Nature remains neutral with regard to jurisdictional claims in published maps and institutional affiliations. 